\title{
Digitalization and robotization in the automation of energy facilities
}

\author{
Alexander Bogdanov ${ }^{1, *}$, Kamil Gilfanov ${ }^{1}$, and Tagir Latypov ${ }^{1}$ \\ ${ }^{1}$ Department of Automation of technological processes and production, Kazan State Power Engineering University, Russia
}

\begin{abstract}
The paper presents the typical technologies of Industry 4.0. The results of a study of publications and materials on the use of digital twins, virtual reality and robotization in energy are presented. The digitalization of energy is considered on the example of the use of digital twins, virtual reality simulators and being developed robotic solutions. Presented the position of the authors on the conceptual combination of these technologies and, as a result, the renewal of classical dispatching in automated control systems of energy facilities in accordance with the ideology of the Industry 4.0.
\end{abstract}

\section{Introduction}

The transition to Industry 4.0 is a global event affecting all major countries in the world. Changes are also taking place in Russia and the attention of the state has been drawn to this event.

In 2017, the digitalization of the economy was included in the list of the main direction of the country's strategic development until 2025. At the same time, the government approved the program «Digital Economy» [1].

The Fourth Industrial Revolution is usually described by the widespread use of such technologies in industry and everyday life as:

- Big Data and cloud computing;

- Internet of things;

- Virtual and augmented reality;

- Blockchain;

- Artificial intelligence and robotics;

- Additive Manufacturing.

Almost all of the above components relate to digitalization. It means that digitalization is a fundamental part of the Industry 4.0 architecture. The other but is also associated with the digitalization element of The Fourth Industrial Revolution is robotics.

The conversion of all sectors of the fuel and energy complex is also part of Industry 4.0. To understand the prospects and get the ability to predict the development of energy automation in the context of The Fourth Industrial Revolution, it's important to explore the possibilities of digitalization and robotization of energy.

\section{Objects and Methods of Research}

Automation of the energy complex initially assumed automatic control of parameters and dispatching. But the accompanying elements of The Fourth Industrial Revolution (the development of microelectronics and the global information network) have added new opportunities for digitalization and robotization of the energy industry.

Based on the analysis of open information sources [1, $2,3,4,5,6]$ the following developing digital solutions for energy can be identified:

- Common Information Model;

- Digital substation;

- Modeling and forecasting of power facility parameters using a digital model (digital twin);

- Virtual reality simulator;

- Intelligent accounting;

- Algorithmic trading;

- Digital channels of communication with the customer;

- Digital payments;

- Predictive service;

- Smart demand and load management;

- Smart Grid;

- Integrating an electric car into the electric grid;

- Analysis and optimization of consumption;

- Production of individual equipment elements using additive technologies;

- Robotic infrastructure diagnostics;

- Data protection and hardware protection against cyber threats;

- Improving the efficiency of production personnel.

One of the most comprehensive solutions in the digitalization of energy is smart grid [2, 3].

The Institute of Electrical and Electronics Engineers (IEEE) defines the concept of smart grids as electrical networks that meet the requirements of energy-efficient and economical operation of the power system through coordinated management using modern two-way switching between substations, accumulating sources and consumers.

The basic technological element of the digital power grid is an intelligent electricity metering system. The

\footnotetext{
* Corresponding author: ban.mic@mail.ru
} 
sources of primary information in this system are smart meters and sensors united in a common network. Such a system contributes to the rapid formation of a reliable volume of services, multi-tariff accounting and other functions. This solution should lead to an increase in the reliability of the power system and the quality of electricity.

The main differences between smart grid and traditional power grid:

- Integrated use of centralized and distributed generation within a single integrated power system;

- The emergence of an active consumer;

- Methods of forestalling, technologies of control and management, accounting and diagnostics of the state of the power system and its elements, allowing to ensure the process of their self-healing and self-treatment;

- Dispersal and localization of control functions in the power grid.

An example of one of the stages in the development of the smart grid is the introduction of "smart electric meters". In Russia, about 2.7 million commercial devices are already equipped with smart solutions.

Another well-known solution in the digitalization of energy is a digital substation $[1,7,8,9,10,11,12,13$, $14,15]$.

The term "Digital substation" refers to the digital organization and interaction of technological systems of a substation (such as IACS, relay protection and automation, etc.) within each system and between systems. The work and management of such facilities is based on the software and technical complex of the digital substation divided into structural levels (process, accession and substation), which are combined through segments of the local-computing network Ethernet.

Based on the analysis, it is possible to distinguish the distinctive features of digital substations:

- Remote digital control of switches and switching machines;

- Automated (and, in the long term, robotic) monitoring of the technical condition;

- Automated system for monitoring and forecasting the quality and accounting of electricity;

- Cybersecurity system.

Examples of such substations are:

- Substation 110/20 kV Medvedevskaya (Moscow, Skolkovo);

- Substation $110 / 10 \mathrm{kV}$ named after M. P. Smorgunov (Solontsy, Krasnoyarsk region);

- Substation 500 kV Tobol (Tobolsk);

- Substation $110 \mathrm{kV}$ Yuzhnaya (Cherepovets).

One of the innovations in energy associated with The Fourth Industrial Revolution is digital twins [5, 16, 17, 18]. Despite the long-standing appearance of the first prototypes and ready-made solutions based on digital twins, it's not yet possible to say that this element of Industry 4.0 has become widely used in Russia.

Digital twins can become an important and necessary tool for ensuring effective digitalization of energy facilities.

Digital twins of individual devices used on energy objects will help track their condition, predict failure and signal the need for replacement.
Digital twins can help organize effective control and management in the complex of all devices located in the space of the object. At the same time, the digital twin, thanks to its simulations of possible and unforeseen situations and operational modes will not only improve the efficiency of management in the online mode, but also predict behavior in different situations, take into account the impact of various external and internal factors, timely assess the level of possible damage or residual resource.

The digital twin, due to its high accuracy, makes it possible to get much closer to a real object, providing a difference between the results of virtual and real tests within the $\pm 5 \%$. This is achieved and verified by the analysis of the readings of measuring devices from a real object. For example, the accuracy of digital models in the automotive industry is tested by $\sim 500$ sensors. The use of digital twins has resulted in a significant reduction in the volume of real tests. For example, the leaders of the global automotive industry in 2007 had a ratio of the number of real and virtual tests of 100 to 100 and 5 to 10 000 in 2017.

An example of the use of digital twins in the energy sector is the ELVIS (Electricity Verkko Information System) project in Finland. Data from SCADA, ArcGIS, and Maximo were fed into a single CIM model database. This information was used to maintain the network and perform various calculations. As a result, productivity has increased, costs have decreased, electric power transmission reliability and business process efficiency have improved.

An interesting and promising solution is the combination of virtual reality and digital twins. Virtual reality technology has been used in various industries for quite a long time [19, 22, 23, 29, 30, 31].

Virtual reality has become the most popular in the entertainment industry:

- Games;

- Cinema;

- Sports broadcasts and shows;

- Social networks.

Virtual reality creates the effects of:

- Presence;

- Immersion:

- Concentration of attention.

Thanks to virtual reality technology, the user feels inside the virtual space.

Thanks to the use of various sensors, the recognition of movements, emotions and gestures of the user is achieved.

Virtual reality helps to focus the user's attention on the specified elements.

The advantage of this technology is the visibility and the ability to simulate various situations. As a result, virtual reality is used in training and advanced training of personnel in the form of exercise systems. For example, in medicine, students can hone their skills on virtual simulators with tactile feedback. Another similar example is the use of virtual reality to facilitate the rehabilitation and treatment of patients with personality disorders. The patient finds himself in a virtual space in a specially created stressful situation by doctors. 
The limited factor for more mass distribution of virtual reality remains the high price of the necessary equipment - a virtual reality helmet and a powerful enough computer.

The most well-known solution for the use of virtual reality in the energy sector is virtual simulators for the personnel of an electric substation [19, 29].

Kazan State Power Engineering University has developed a prototype of such a simulator for a $110 / 35 / 10 \mathrm{kV}$ substation.

The advantages of such equipment:

- Safety;

- On-the-job training;

- Simulation of any situation, including emergency situations;

- Modeling any real or projected object with specified detail;

- Formation of motor skills interaction with substation equipment.

To improve efficiency, the developers of virtual reality simulators for the electric substation are trying to achieve:

- Realistic;

- Interactivity;

- Detailing;

- Visibility;

- Presence effect.

The virtual reality simulator should create a feeling in the user of the presence on the object and the reality of what is happening.

The user must be able to interact with the object. For example, to carry out operational switching.

Detailing the virtual space helps to increase the sense of presence and efficiency of learning. The user in the real situation should have the same tools and surrounding space as in the virtual simulator.

The ability to see the physical processes taking place inside the object is rarely realized in virtual reality simulators for electrical substations. But this possibility allows you to better understand the design of the equipment and the causes of accidents.

Thanks to the sense of presence, an algorithm of actions is formed, the necessary real movements for different events are remembered.

Integrating virtual reality into a digital twin adds visibility and effect to being in the space of an object. Combining such a software package with classic automation and robotics solutions makes it possible to transfer modern dispatching to a new level.

Dispatching based on the combination of digital twin, virtual reality and robotics is especially relevant for energy facilities geographically distributed in large space and remote from populated areas.

As a result of the study of literary sources [24-38] the following robotic solutions can be identified in such a complex:

- Robots designed to diagnose and maintain power lines;

- Robots designed to check the condition of wind turbines, to clean wind turbine blades;

- Robots designed to clean solar panels, to turn the panels while tracking the sun;
- Robots designed to diagnose and maintain nuclear reactors.

But the development and increasing availability of microelectronic component base, software creates new opportunities for robotics and the emergence of new robotic solutions.

According to the design, the following technical solutions can be distinguished:

- Flying, ground, underwater platform or using different types of captures;

- Mobile, stationary platform;

- Modular reconfigurable, modular nonreconfigurable platform.

Examples of such robots for servicing high-voltage power lines: lines;

- Expliner, inspection and condition check of power

- LineScout, snow removal, tightening of bolted connections, cleaning of wires from various foreign objects.

Important for the development of this area is the training of teams of developers of various robotic solutions using non-expensive components. For example, capture or move components.

At the Kazan State Power Engineering University, on the basis of the Youth Innovation Center students develop various prototypes that can later be used to automate energy facilities.

The integration of robotic solutions and a digital twin with virtual reality enables personnel to remotely service an energy facility.

\section{Results and Discussion}

Digital twins using virtual reality add new opportunities in training and skills development of personnel of energy facilities.

The introduction of virtual reality into a digital twin with the addition of robotic elements will take the automation of energy facilities to a new level in accordance with the ideology of Industry 4.0.

In this case, the operator will be able to remotely monitor the condition of several dozen electric substations for example and, if necessary, including virtual reality mode remotely control robotic devices to replace components and current repairs.

Such an organization of interaction of digital twin, robotic devices and real object is possible not only on an electrical substation. But in order to successfully implement such an approach, careful and gradual preparatory work is required. Digital twins of devices should be prepared, and robotic solution should be developed and implemented. Then a digital twin of the object should be created entirely using virtual reality.

The training of personnel capable of creating the considered technical solutions also plays an important role. Considerable attention is paid to the creation of software products and the training of relevant developers in Russia. Unfortunately, robotics can't boast the same thing yet. 
Combining the digital twins of energy facilities will create a digital twin of the energy network as a whole. This will help to improve the manageability and efficiency of power grids of Russia.

\section{Conclusion}

The paper presents the results of the authors'study of publications and materials on the application of digitalization and robotics in energy, on the basis of which the main elements for the formation of the concept of dispatching energy facilities with the use of digital twins with virtual reality and elements of robotics are highlighted.

The main methods and mechanisms for implementing solutions based on digital twins, virtual reality and elements of robotics in energy are considered. The position of the authors on the assessment of trends and prospects for the development of automation and dispatching of energy facilities in the framework of the transition to Industry 4.0 is presented.

This paper didn't investigate the impact of energy chance on other industries as part of the transition to Industry 4.0 .

\section{References}

1. A. Martynova, Electric Power Industry 4.0: Switch to Digital, Atomic Expert, 5 (66), 34-40 (2018)

2. E. Chistova, To transmit with the mind, Information and analytical publication, appendix to the scientific journal Atomic Energy, 7 (68), 22-27 (October 2018)

3. B.B. Kobets, I.O. Volkova, Innovative development of electric power industry on the basis of the Smart Grid concept: Monograph (Moscow: IAC Energia, 208, 2010)

4. A.N. Belyaev, R.A. Bogomolov, CIM in Russia: experience JSC "so UES" for the implementation and maintenance of integrated information model of the UES of Russia in a hierarchical Supervisory control, plans and prospects, the electric power industry through the eyes of youth - 2019, Proceedings of jubilee $\mathrm{X}$ international. Sci. - tech. conf., in 3 vols., Irkutsk, IRNITU Publishing House, 38-43 (16-20 September 2019)

5. E.B. Tishchenko, "Smart" path to Victory, Information and analytical journal Construction in the Nuclear Industry, Private Institution of the State Atomic Energy Corporation Rosatom "OCCS", 1, 12-13 (2018)

6. O.A. Zhukov, Aspects of digitalization of the electric power industry and electrotechnical Expertise, Eurasian Scientific Association, 5-2 (51), 121-125 (2019)

7. V.O. Golovshchikov, Digital substation - the main element of the digital electric power system, Modern technologies and scientific and technical progress, 1, 224-225 (2019)

8. V.A. Fedulova, O.V. Novikova, Introduction of the Digital Substation technology: complex tests of the
Nizhny Novgorod Hydroelectric Power Station digital test site, Energy Economics and Energy Saving, Materials of the International Scientific Conference, $72-75$ (2018)

9. L.L. Orlov, Innovative development: from automation systems to digital substations, Automation in Industry, 4, 39-40 (2012)

10. A.V. Ankushev, B.V. Zherebtsov, A.S. Kizurov, Transition from traditional substations to digital substations using the IEC Protocol, Collection of articles of the II All-Russian (national) scientific and practical conference "Modern scientific and practical solutions in the agro-industrial complex", State Agrarian University of the Northern TransUrals, 285-289 (2018)

11. V.I. Dubrov, R.G. Ohanyan, N.D. Narakidze, G.K. Aleksanyan, Development of an information system for a software and hardware model of a digital substation, Proceedings of the XV International Conference NIDays 2016, Moscow, 300-302 (2016)

12. E.N. Sosnina, R.Sh. Bedretdinov, I.A. Lipuzhin, Modeling of energy-efficient modes of operation of a digital electric substation, Fedorov Readings-2013, XLIII/International Scientific and Practical Conference, Moscow, Publishing House of the MEI, 155-159 (6-8 November 2013)

13. O.N. Titarenko, I.A. Murtazaev, Digital substations - an important element of an intelligent power system, Power installations and technologies, 1, 58$63(2020)$

14. A.O. Yakovlev, On some features of the use of digital substations, Energy efficiency and Energy saving in modern production and society Materials of the international scientific and practical conference, Under the general editorship of V.A. Gulevsky, 143-148 (2019)

15. A.V. Pazderin, P.V. Murzin, I.N. Odinaev, F.Z. Bobokalonov, Research directions for improving the reliability of digital substation information, Electrotechnical Systems and Complexes, 45 (4), 411 (2019) DOI: 10.18503/2311-8318-2019-4(45)-411

16. K.S. Ponomarev, A.N. Feofanov, A Digital twin of the production as a tool of digitalization of technological processes of an enterprise, Current trends and prospects of development of science, engineering and technology: proceedings of the International scientific-practical conference, ed. by E.P. Tkachova, Belgorod, Agency for Advanced Scientific Research (APNI), LLC, 141-144 (2018)

17. V.E. Romanovskaya, "Digital Twin" as the basis of digital Design and modeling, Digital technologies in economy and industry (ECOPROM-2019), Proceedings of the National scientific and Practical conference with international participation, Edited by A.V. Babkin, 208-214 (2019)

18. E.P. Grabchak, E.L. Loginov, Digital twins of Nuclear power plants and thermal power plants as elements of digital agglomerations in the energy super system, Modern problems of electric Power industry and Ways to solve them: materials of the $\mathrm{V}$ 
All-Russian Scientific and Technical Conference, Makhachkala, DSTU, 155-159 (2019)

19. R.M. Muratov, I.A. Ryabykh, Virtual reality simulator for working with high-voltage equipment, Radio Electronics, Electrical Engineering And Power Engineering, P 154 Twenty-fifth International Scientific and Technical Conference conf. of students and postgraduates, Moscow, Tez. dokl., Moscow, LLC "Center for Printing Services "Raduga", 600 (14-15 March 2019)

20. A.V. Aliev, A.A. Shchukin, D.V. Kalinin, Yu.N. Borsky, M.Yu. Lavrovsky, D.V. Privalova, The use of virtual reality in the development of a simulator for the operational personnel of the unloading and loading machine for RMBK-1000 reactors, Issues of atomic science and Technology, Physics of Nuclear Reactors, 65-69 (2007)

21. G.A. Koloskova, Y.U. Koloskova, VR as an additional training in the energy sector, Actual science, 7 (36), 28-31 (2020)

22. A.S. Sadriev, Virtual reality technologies in modern education, Bulletin of Scientific Conferences, 2-2 (18), 95-97 (2017)

23. D.Y. Andrushko, Application of virtual and augmented reality technologies in the educational process: problems and prospects, Scientific Review, Pedagogical Sciences, 6, 5-10 (2018)

24. M.L. Shit, S.G. Shkolnik, E.S. Andreev, Specialized robots in power engineering, Problems of regional Power Engineering, 1 (24), 63-70 (2014)

25. V.F. Shishlakov, S.V. Solon, D.G. Shavliashvili, L.M. Il'in, Cyber-physical systems in the power industry, Zavalishina reading (SB. Dokl./SPb.: SUAE, 5, 2017)

26. A.A. Morozov, D.A. Rusakov, N.A. Kazachek, Software and hardware complex based on mobile robots with variable chassis geometry, Proceedings of the VI International Scientific and Technical Conference. conf. of young scientists, Omsk, Publishing house of the Omsk state technical University, 146-150 (2016)

27. S.A. Kulabukhov, M.V. Bobyr, A stereo vision device for a mobile robot navigation system, Modern innovations in science and technology, 106110 (2018)

28. A.M. Romanov, Review of hardware and software for modern control systems of robotic complexes of various scales and purposes, Part 2, Service Robotics, Russian Technological Journal, 7 (6), 6886 (2019)

29. A.N. Bogdanov, I.A. Ryabykh, A.I. Galiev, Education Quality Improvement Due To Automated Virtual Reality System, 2019 International Scientific And Technical Conference Smart Energy Systems, SES 2019 Kazan, 05024 (18-20 September 2019) DOI: $10.1051 / \mathrm{e} 3$ sconf/201912405024

30. R.K. Atamuratov, The educational advantages of virtual reality technologies, International scientific review of the problems and prospects of modern science and education, Problems of science, 90-92 (2020)
31. D. Velev, P. Zlateva, Virtual Reality Challenges in Education and Training, International Journal of Learning and Teaching, 3 (1), 33-37 (March 2017)

32. T.T. Zielinska, History of service robots and new trends, Novel Design and Applications of Robotics Technologies, IGI Global, 158-187 (2019) DOI: 10.4018/978-1-5225-5276-5.ch006

33. A. Kulachinskaya, I.G. Akhmetova, V. Y. Kulkova, V.Y., S.B. Ilyashenko, The challenge of the energy sector of russia during the 2020 covid-19 pandemic through the example of the republic of tatarstan: Discussion on the change of open innovation in the energy sector, Journal of Open Innovation: Technology, Market, and Complexity 6(3),60 (2020)

34. E. Bazukova, Y. Vankov, Increasing the reliability of thermal energy transportation systemstaking into account forecasting the properties of thermal insulation during operation, E3S Web of Conferences 216,01078 (2020)

35. I.V. Shvetsov, E.V. Garnyshova, E.V. Izmaylova, E.V., Y.V. Vankov, A.R. Zagretdinov, Reducing labor input of monitoring condition of heat exchange equipment surfaces, IOP Conference Series: Materials Science and Engineering 939(1),012072 (2020)

36. T.V. Tabachnikova, E.I. Gracheva, O.V. Naumov, A.N. Gorlov, Forecasting technical state and efficiency of electrical switching devices at electric complexes in oil and gas industry, IOP Conference Series: Materials Science and Engineering 860(1),012014 (2020)

37. I.N. Voytyuk, A.V. Kopteva, A.N. Skamyin, "Emergency Response Plan" Automated System for Oil Production and Transportation Enterprises, Journal of Ecological Engineering 22(1), p. 76-82 (2020)

38. Yu.V. Gulkov, A.V. Turysheva, P.B. Gurkin, Electric power quality control in electro-technical complexes of oil processing plant, IOP Conference Series: Materials Science and Engineering 643(1),012001 (2019) 